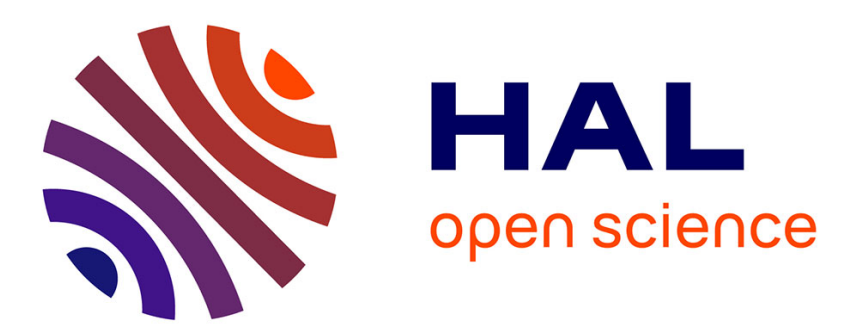

\title{
Investigating the interactions between data assimilation and post-processing in hydrological ensemble forecasting
}

François Bourgin, Maria-Helena Ramos, Guillaume Thirel, Vazken

Andréassian

\section{- To cite this version:}

François Bourgin, Maria-Helena Ramos, Guillaume Thirel, Vazken Andréassian. Investigating the interactions between data assimilation and post-processing in hydrological ensemble forecasting. Journal of Hydrology, 2014, 519 (Part D), pp.2775-2784. 10.1016/j.jhydrol.2014.07.054 . hal-02600032

\section{HAL Id: hal-02600032 \\ https://hal.inrae.fr/hal-02600032}

Submitted on 1 Dec 2020

HAL is a multi-disciplinary open access archive for the deposit and dissemination of scientific research documents, whether they are published or not. The documents may come from teaching and research institutions in France or abroad, or from public or private research centers.
L'archive ouverte pluridisciplinaire HAL, est destinée au dépôt et à la diffusion de documents scientifiques de niveau recherche, publiés ou non, émanant des établissements d'enseignement et de recherche français ou étrangers, des laboratoires publics ou privés. 


\section{Accepted Manuscript}

Investigating the interactions between data assimilation and post-processing in hydrological ensemble forecasting

F. Bourgin, M-H. Ramos, G. Thirel, V. Andréassian

PII: S0022-1694(14)00588-5

DOI: http://dx.doi.org/10.1016/j.jhydrol.2014.07.054

Reference: HYDROL 19785

To appear in:

Journal of Hydrology

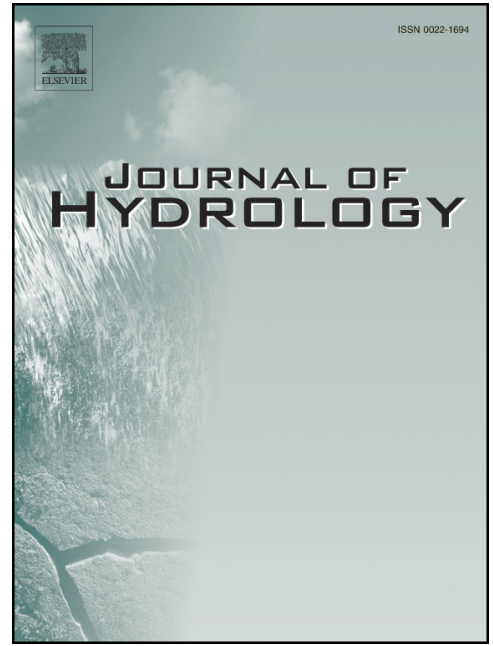

Please cite this article as: Bourgin, F., Ramos, M-H., Thirel, G., Andréassian, V., Investigating the interactions between data assimilation and post-processing in hydrological ensemble forecasting, Journal of Hydrology (2014), doi: http://dx.doi.org/10.1016/j.jhydrol.2014.07.054

This is a PDF file of an unedited manuscript that has been accepted for publication. As a service to our customers we are providing this early version of the manuscript. The manuscript will undergo copyediting, typesetting, and review of the resulting proof before it is published in its final form. Please note that during the production process errors may be discovered which could affect the content, and all legal disclaimers that apply to the journal pertain. 


\title{
Investigating the interactions between data assimilation and post-processing in hydrological ensemble forecasting
}

\author{
F. Bourgin* \\ M-H. Ramos \\ G. Thirel \\ V. Andréassian \\ Irstea, UR HBAN, 1 rue Pierre-Gilles de Gennes, CS 10030, F-92761 Antony Cedex, \\ France
}

\begin{abstract}
We investigate how data assimilation and post-processing contribute, either separately or together, to the skill of a hydrological ensemble forecasting system. Based on a large catchment set, we compare four forecasting options: without data assimilation and post-processing, without data assimilation but with post-processing, with data assimilation but without post-processing, and with both data assimilation and post-processing. Our results clearly indicate that both strategies have complementary effects. Data assimilation has mainly a very positive effect on forecast accuracy. Its impact however decreases with increasing lead time. Post-processing, by accounting specifically for hydrological uncertainty, has a very positive and longer lasting effect on forecast reliability. As a consequence, the use of both techniques is
\end{abstract}

\footnotetext{
*Fax number: +33140966258

Email addresses: francois.bourgin@irstea.fr (F. Bourgin)
} 
recommended in hydrological ensemble forecasting.

Key words: hydrological ensemble forecasting, data assimilation, post-processing, ensemble dressing, uncertainty propagation

\section{Introduction}

\subsection{Addressing uncertainties in hydrological ensemble forecasting}

Developing and improving operational hydrological ensemble forecasting

4 systems is a critical step toward better decision-making and risk management.

${ }_{5}$ The skill of operational hydrological ensemble forecasting systems is limited

6 by two main sources of uncertainty (Krzysztofowicz, 1999): meteorological 7 uncertainty and hydrological uncertainty. From a pragmatic point of view,

8 the need to properly account for these two main sources of uncertainty arises

20 has been introduced fifteen years ago by Krzysztofowicz (1999). Since then, 21 a number of other hydrological uncertainty processors have been proposed 
${ }_{45}$ based on distributions of past model errors and, this way, build probabilis-

(Montanari and Brath, 2004; Montanari and Grossi, 2008; Solomatine and Shrestha, 2009; Coccia and Todini, 2011; Morawietz et al., 2011; Weerts et al., 2011; Ewen and O'Donnell, 2012; Pianosi and Raso, 2012; Smith et al., 2012; Van Steenbergen et al., 2012; Yan et al., 2012), but their use is not widespread for operational ensemble forecasting.

Although generally dealt with separately, statistical post-processing and data assimilation (also called real-time model updating in the engineering community) can be intrinsically related in the hydrological forecasting framework. Both represent techniques that may be used in a forecasting system to improve the quality of the forecasts (i.e., to provide more accurate and reliable forecasts) and to, ultimately, enhance the usefulness of the forecasts in decision-making. Since forecasting deals with an uncertain future, these techniques aim to bring additional information to the forecast procedure and take into account the various uncertainty sources (or at least the major uncertainty sources) affecting the forecasting chain. This is usually achieved by merging information from model and observations.

While data assimilation and post-processing share a general goal, the techniques applied may differ in the practice of hydrological forecasting. These differences usually draw the separation between what is defined as data assimilation and what is defined as post-processing in a modelling framework. The definitions used in this study are the following: we use the term "postprocessing" when using the hydrological uncertainty processor (Section 2.4), whose primary purpose is to dress deterministic forecasts with uncertainty tic forecasts. "Data assimilation" refers to techniques applied to perform 
70 from the past), and then applied to ensemble forecasts to obtain the total 71

the updating of the system before it issues a deterministic forecast. Here it concerns the state updating of the hydrological model and a model error correction applied to its output (Section 2.3).

The fact that data assimilation has the potential to improve real-time streamflow forecasting is widely accepted (see Liu et al., 2012, for a review). In contrast to probabilistic and ensemble-based data assimilation methods (e.g., Weerts and El Serafy, 2006; Salamon and Feyen, 2010; Moradkhani et al., 2012; Vrugt et al., 2013), deterministic updating schemes are designed to improve forecasts without producing probabilistic outputs. They may be easier to implement, mainly operationally, but at the price of leaving the uncertainty quantification issue unanswered. In these cases, the use of statistical post-processing methods together with data assimilation procedures provides a way to reduce and quantify the predictive uncertainty in the hydrological forecasts.

\subsection{Integrating uncertainties in hydrological ensemble forecasting}

"Ensemble dressing" is an intuitive and operationally-appealing method that allows integration of uncertainties from hydrological modelling and meteorological (ensemble) forcing. The main difference with other ensemblebased post-processors (e.g., Wang and Bishop, 2005; Fortin et al., 2006; Brown and Seo, 2010; Boucher et al., 2012; Brown and Seo, 2013) is that, for ensemble dressing, hydrological modelling errors are assessed separately, and later combined with ensemble forecasts. Distributions of modelling errors are obtained from long time series of simulated and observed data (i.e., learning predictive distribution. 


\subsection{Aim and scope of the study}

95 This study aims to shed light on the interactions between data assimi96 and tested to improve the skill of hydrological ensemble forecasting systems. For instance, Reggiani et al. (2009) present a Bayesian ensemble uncertainty processor for medium-range ensemble flow forecasts in the Rhine river basin. Hopson and Webster (2010) use an uncertainty processor based on the knearest neighbours (k-NN) resampling method to dress probabilistic mediumrange forecasts for two large basins in Bangladesh. Zalachori et al. (2012) compare different strategies based on pre-and post-processing methods to remove biases in a streamflow ensemble prediction system developed for reservoir inflow management in French catchments, while Pagano et al. (2013) present a hydrological application of ensemble dressing for 128 catchments in Australia.

The studies mentioned above have in common the fact that they focus on post-processors for operational applications and on the overall evaluation of the quality of post-processed forecasts. Like in the studies that develop and test data assimilation techniques, most of the forecast assessment is on the benefits (in terms of quality) that post-processors or data assimilation may bring to forecast quality (accuracy, reliability, sharpness, etc.) at fixed forecast lead times. Little is known about the interactions between these two components of a forecasting system and the impacts of implementing both post-processing and data assimilation on the performance of the forecasts along the forecast lead times. lation and post-processing in hydrological ensemble forecasting. We address

In recent studies, the use of ensemble dressing has been implemented 
the following questions:

1. How does data assimilation impact hydrological ensemble forecasts?

2. How does post-processing impact hydrological ensemble forecasts?

3. How does data assimilation interact with post-processing to improve the quality and skill of hydrological ensemble forecasts over the forecast lead times?

We address these questions with the help of a large set of catchments, making it possible to draw more general and robust conclusions.

\section{Data and methods}

\subsection{Data set}

A set of 202 unregulated catchments spread over France was used (Figure 1). The catchments represent various hydrological conditions, given the variability in climate, topography, and geology in France. This set includes fast responding Mediterranean basins with intense precipitation as well as larger, groundwater-dominated basins. Some characteristics of the data set are given in Table 1. Catchments were selected to have limited snow influence, since no snowmelt module was used in the hydrological modelling (Section 2.3).

Potential evapotranspiration (PE), precipitation, and discharge data were available at hourly time steps over the 1997-2006 period. Temperature inputs originate from the SAFRAN reanalysis (Vidal et al., 2010). PE was estimated using a temperature-based formula (Oudin et al., 2005). Precipitation data come from a reanalysis dataset recently produced by Météo-France based on 


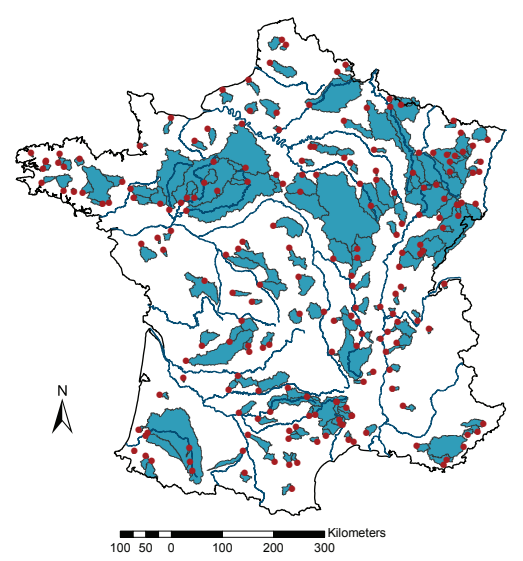

Figure 1: Locations of the 202 French catchments used in this study (dots correspond to the gauging stations, and blue color is catchment areas).

weather radar and rain gauge network (Tabary et al., 2012). River discharge data were extracted from the HYDRO national archive (www.hydro.eaufrance.fr).

\subsection{PEARP, the Météo-France ensemble forecast}

A short-range meteorological ensemble prediction system, the MétéoFrance PEARP EPS (Nicolau, 2002), was used to produce hydrological ensemble forecasts. The PEARP EPS runs once a day at 18:00 UTC; it has 11 members, a $60 \mathrm{~h}$ forecast range, and a $0.25^{\circ}$ (ca. $25 \mathrm{~km}$ in France) grid resolution. A spatial disaggregation to an $8 \mathrm{~km} \times 8 \mathrm{~km}$ grid, which includes bias correction, was applied to the PEARP forecasts. Bias correction was applied to precipitation forecasts using a multiplying factor obtained from a comparison between the mean of the PEARP ensemble and the Météo-France SAFRAN reanalysis over a complete year (March 2005 to March 2006). Details can be found in Thirel et al. (2008). PEARP forecasts were available 


\begin{tabular}{lccccc}
\hline & \multicolumn{5}{c}{ Percentiles } \\
& 0.05 & 0.25 & 0.50 & 0.75 & 0.95 \\
\hline Catchment area $\left(\mathrm{km}^{2}\right)$ & 31 & 108 & 245 & 653 & 3761 \\
Mean annual precipitation (mm/y) & 725 & 848 & 957 & 1158 & 1465 \\
Mean annual potential evapotranspiration (mm/y) & 645 & 668 & 701 & 745 & 828 \\
Mean annual runoff (mm/y) & 143 & 232 & 344 & 513 & 964 \\
Q/P ratio & 0.18 & 0.27 & 0.35 & 0.47 & 0.68 \\
P/PE ratio & 0.93 & 1.14 & 1.36 & 1.66 & 2.14 \\
Mean elevation (m) & 86 & 155 & 306 & 535 & 843 \\
Discharge autocorrelation at $48 \mathrm{~h}$ & 0.28 & 0.5 & 0.66 & 0.81 & 0.94 \\
\hline
\end{tabular}

Table 1: Characteristics of the 202 catchments. P-precipitation, PE-potential evapotranspiration, Q-discharge.

over the 2005-2009 period, but only the period matching the observed data could be used here, i.e. from August 2005 to December 2006.

PEARP forecasts were already used at the daily time step in recent hydrological studies (Thirel et al., 2008; Randrianasolo et al., 2010). Overall, they showed good quality over France at this time step. The quality for shortterm forecasting at hourly time steps (with either raw and post-processed forecasts) is first assessed here.

\subsection{The GRP rainfall-runoff forecasting model}

The GRP model is a continuous, lumped storage-type model designed for flood forecasting. Its structure was derived from the GR4J model (Perrin et al., 2003) and is composed of a production function and a routing function.

The production function consists of a non-linear soil moisture accounting (SMA) reservoir and a volume adjustment coefficient. The routing function 
includes a unit hydrograph and a non-linear routing store. The GRP model uses catchment areal rainfall and PE as inputs; it is parsimonious with three parameters to be calibrated against observed data: one in the production function (the volume adjustment coefficient) and two for the routing function (the base time of the unit hydrograph and the total capacity of the routing store). In this study, the three free parameters were calibrated for each catchment by minimizing the root mean square errors (RMSE) during the first five years of available data (1997-2001).

Importantly, the hourly version of the GRP model uses together two data assimilation procedures for flood forecasting. The first exploits the last available observed discharge to directly update the routing store state, and the second exploits the last relative error to correct the model output with a multiplicative coefficient. More details about the forecasting model GRP and the two assimilation procedures can be found in Berthet et al. (2009).

\subsection{Hydrological uncertainty processor}

We used a hydrological uncertainty processor (HUP) to evaluate the conditional errors of the hydrological model. Only hydrological uncertainty is considered by the HUP here since the model is run with observed weather data. The meteorological uncertainty is subsequently considered through the joint use of the HUP with the PEARP forecasts, as described in Section 2.5. The HUP used here is a data-based and non-parametric method that was applied by Andréassian et al. (2007) to assess model simulation uncertainties and compute empirical uncertainty bounds to flow simulations. Here it is applied to produce probabilistic flow forecasts. The basic idea is to estimate empirical quantiles of relative errors stratified by different flow groups. The 
171

Satep 1. The hydrological model is run with observed weather data as input and

s\&tep 2. The time series is stratified into 20 groups according to the magnitude of

Satep 3. Within each group, an empirical distribution of relative errors is defined

step 4. Once defined during the training period, the empirical quantiles of rel-

HUP is trained during the period used for calibrating the parameters of the hydrological model (1997-2001). Note that it is possible that this approach yield optimistic uncertainty estimates, since errors are usually larger on an independent period than during the calibration period. Since forecast error characteristics vary with forecast range when data assimilation is used, the HUP is trained at several lead times separately.

For each catchment, the HUP is trained as described below: the time series of relative errors is evaluated: $Q_{f c t} / Q_{o b s}$, where $\left(Q_{f c t}\right.$, $\left.Q_{o b s}\right)$ are the pairs of discharge forecasts and observations. the $Q_{f c t}$. The limits of each group are fixed so that each group contains the same number of values. and 99 quantiles are estimated (corresponding to the percentiles 1\%, $2 \%$, ... $98 \%, 99 \%)$.

Application of the HUP for another forecast period is described by the last step: ative errors can be applied to any forecast discharge at a certain lead time. The limits of each group are the same as those obtained during the training period. Note that when data assimilation is not used, the empirical quantiles of relative errors are the same whatever the forecast lead time is. Given a discharge forecast $Q_{f c t}$, we first determine the flow 

${ }_{217}$ semble forecasts is done over an independent period, the 17 -month period 218 from August 2005 to December 2006.

group $Q_{f c t}$ belongs to; then $Q_{f c t}$ is multiplied by the 99 quantiles of relative errors; the 99 values obtained describe the predictive distribution at the considered time step and for a given forecast horizon. In cases of extrapolation (i.e., when the forecast discharge is out of the range of the flow groups defined during the training phase of the HUP), values of relative errors from the nearest flow groups (i.e., the lowest or the highest flow groups) are used.

Preliminary studies carried out to compare this approach to other similar post-processing approaches suggest that it can yield similar results in terms of forecast performance, while being simpler in its application.

\subsection{Ensemble dressing method: an integrator of the meteorological and hy- drological uncertainties}

The ensemble dressing method is used as an integrator of the meteorological and hydrological uncertainties. It consists in two steps. Firstly, each time an ensemble PEARP forecast is available, the hydrological model is run with the ensemble forecast and the HUP is applied, according to Step 4 of Section 2.4, to each of the 11 members of the ensemble for each lead time considered. Secondly, the $11 \times 99$ values obtained at each lead time are pooled together and an empirical cumulative distribution is estimated. From this distribution, 99 quantiles are retained as the members of the dressed ensemble.

Application and evaluation of the ensemble dressing method for the en- 


\subsection{Experiments}

The hydrological ensemble forecast system combines meteorological and streamflow data from observation networks, the Météo-France PEARP ensemble forecast, the GRP rainfall-runoff model with its two data assimilation functions, the hydrological uncertainty processor (HUP) and the ensemble dressing method. Hereafter we will use the term "post-processing" to describe the joint use of the HUP and the ensemble dressing method, while the term "data assimilation" will refer to the two updating techniques used in the GRP model.

In order to assess the benefits of data assimilation and post-processing, considered together or separately, different configurations of the forecasting chain were analysed. Our experiments comprise a chain without data assimilation and post-processing (NoDA-NoPP), without data assimilation but with post-processing (NoDA-PP), with data assimilation but without postprocessing (DA-NoPP), and with both data assimilation and post-processing (DA-PP). The characteristics of the experiments and the acronyms used are given in Table 2.

In particular, the NoDA-NoPP experiment corresponds to the situation where the hydrological model is run in simulation mode, i.e., without using recent streamflow observations for data assimilation, and is then driven by the PEARP ensemble forecast when the forecast is issued. When data assimilation is used, the state of the routing reservoir of the hydrological model is first updated based on the last observed discharge, and the second procedure is then applied separately at each streamflow ensemble member. This structured analysis allows us to identify the influence of data assimilation and 
post-processing separately to assess the benefits of both components when used together in the forecasting chain.

\begin{tabular}{lcc}
\hline & Without data assimilation & With data assimilation \\
\hline Without post-processing & NoDA-NoPP & DA-NoPP \\
With post-processing & NoDA-PP & DA-PP \\
\hline
\end{tabular}

Table 2: Acronyms used for the different experiments used in this study.

\subsection{Forecast evaluation methods}

The evaluation of the performance of probabilistic forecasts should reflect the different facets of probabilistic forecasts. In this study, the forecasts obtained from the four experiments set up (Table 2) were evaluated with both deterministic and probabilistic scores. We aimed to assess the influence of data assimilation and post-processing on the following characteristics of ensemble forecasts: accuracy of the ensemble mean, overall sharpness and reliability of the whole ensemble, and overall forecast quality of the ensemble.

More specifically, we evaluated the accuracy of the ensemble mean values with the relative bias (BIAS) and the normalized root-mean-square error (NRMSE). To assess the overall reliability of the forecasts, we used the Probability Integral Transform (PIT) diagram (see e.g., Laio and Tamea, 2007; Thyer et al., 2009) and an index that quantifies deviation from the ideal case, the alpha score (Renard et al., 2010). The overall sharpness of the forecasts was measured with an index based on the interquartile range that we called normalized mean interquartile range (NMIQR). Finally, we assessed the overall forecast quality of the whole ensemble with the mean Continuous Rank 
Probability Skill Score (mean CRPSS). The mean CRPSS is computed with the unconditional streamflow climatology as the reference. These scores are presented in more details in A.

\section{Results and discussion}

\subsection{Forecast accuracy}

Figure 2 shows the distributions of the two deterministic scores used to assess forecast accuracy: the relative bias (BIAS) and the normalized rootmean-square error (NRMSE). Each score is computed for lead times $6 \mathrm{~h}$, $12 \mathrm{~h}, 24 \mathrm{~h}$ and $48 \mathrm{~h}$ and for all 202 catchments. The distribution of the 202 values is summarized with boxplots.

We note that forecast accuracy decreases with increasing lead time for the four experiments. For NoDA experiments (NoDA-NoPP and NoDA-PP), the loss of performance is quite limited: it is only related to the decreasing performance of the PEARP ensemble precipitation forecasts. For DA experiments (DA-NoPP and Da-PP), the decrease is stronger and the performances converge toward those of NoDA experiments: the effects of the two DA procedures used in the GRP forecasting model vanish with larger horizons; the decrease in performance of the hydrological model is then added to the losses in performance of the PEARP ensemble precipitation forecasts. Figure 2 also reveals that post-processing does not significantly impact forecast accuracy, whether or not DA is used. DA has a much stronger impact on the ensemble mean values than post-processing, especially for shorter lead times and, to a lower extent, for larger lead times. The two DA procedures used in the GRP forecasting model have been designed to improve the performance of deter- 
ministic forecasts and, as it can been seen, they clearly help improving the mean of the ensemble forecasts. Post-processing on the other hand primarily aims to account for hydrological uncertainty. Its capability to reduce overall bias and squared errors in the mean of the ensemble forecasts is limited here. Nonetheless, for all lead times, forecast accuracy is best when DA and PP are used together, which indicates the benefits of the combined use of data assimilation and post-processing.

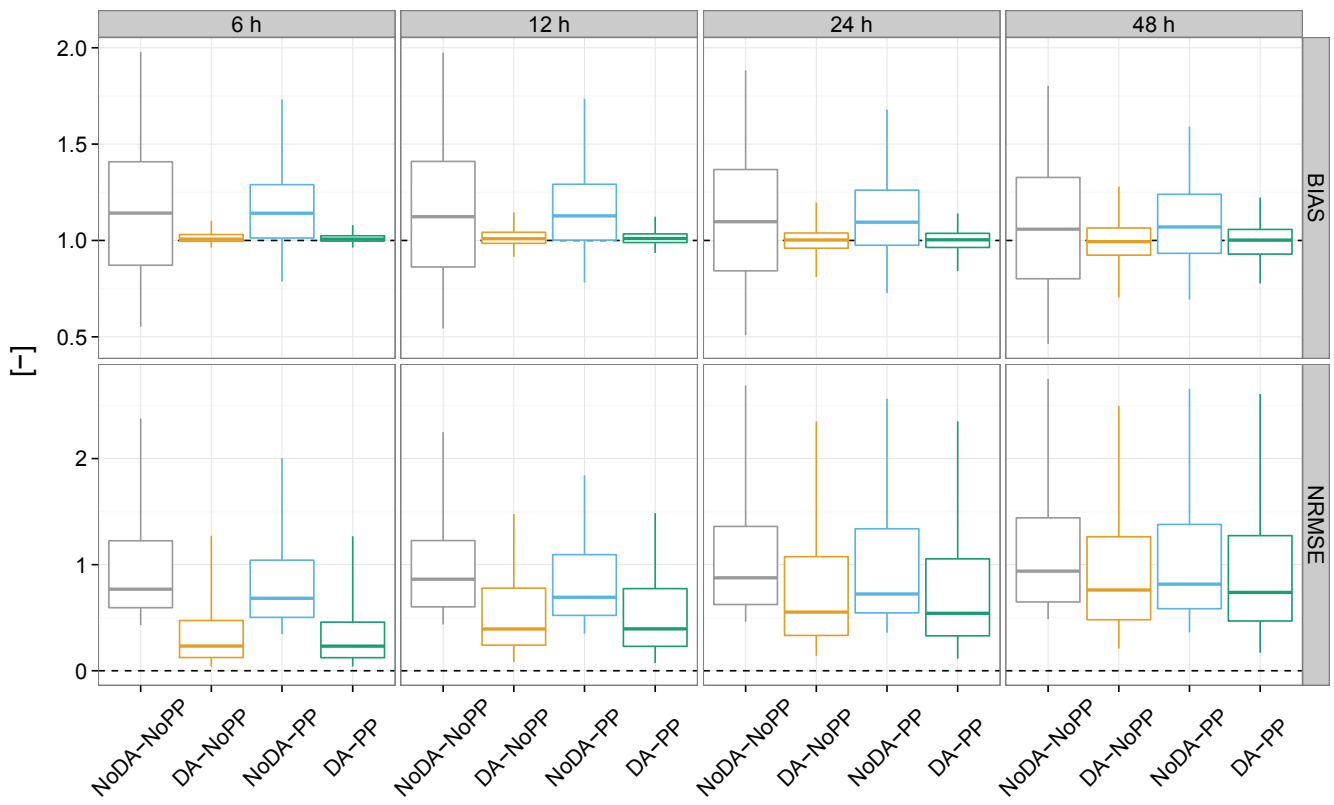

Figure 2: Distributions of two deterministic scores, the relative bias (BIAS) and the normalized root-mean-square error (NRMSE), for ensemble streamflow forecasts from the four experiments (see Table 2) and lead times $6 \mathrm{~h}, 12 \mathrm{~h}, 24 \mathrm{~h}$ and 48 h. Boxplots (5th, 25th, 50th, 75th and 95th percentiles) synthesize the variety of scores over the 202 catchments of the data set. 


\subsection{Reliability}

Figure 3 presents the PIT diagrams obtained for each of the 202 catchments, when considering $24 \mathrm{~h}$ ahead ensemble forecasts. Since similar figures were obtained for the other lead times (not shown).

From Figures $3 \mathrm{a}$ and $3 \mathrm{~b}$, it can be seen that most of the curves are almost horizontal straight lines, while they would follow the bisector (black lines in the graphs) in the ideal case of reliable ensemble predictions. Figures $3 \mathrm{a}$ and $3 \mathrm{~b}$ clearly reveal that the raw ensembles are lacking reliability for all of the catchments. The impact of post-processing on reliability is apparent when looking at the results on Figures $3 \mathrm{c}$ and $3 \mathrm{~d}$ : the curves of the ensemble streamflow forecasts with post-processing follow the ideal situation much more closely than the curves shown in Figures $3 \mathrm{a}$ and $3 \mathrm{~b}$ (ensemble streamflow forecasts without post-processing). It means that the overall reliability of the ensembles is clearly improved with post-processing and this for both cases, with and without DA. A comparison of solely Figures 3c and 3d confirms also the positive impact of data assimilation on the reliability of the ensembles: the PIT curves of the dressed ensembles are substantially closer to the diagonal (perfect reliability) when DA is applied.

The PIT diagrams convey a visual evaluation of the overall reliability of probabilistic forecasts. To quantify it, we used the alpha score, a reliability index that measures the deviation of the PIT curves from the ideal situation. Figure 4 presents the distributions of the alpha scores obtained for each experiment over the 202 catchments. Results in Figure 4 confirm the visual evaluation obtained with the PIT diagrams: the two experiments that do not account for hydrological uncertainty (NoDA-NoPP and DA-NoPP) lack 
(a) NoDA-NoPP

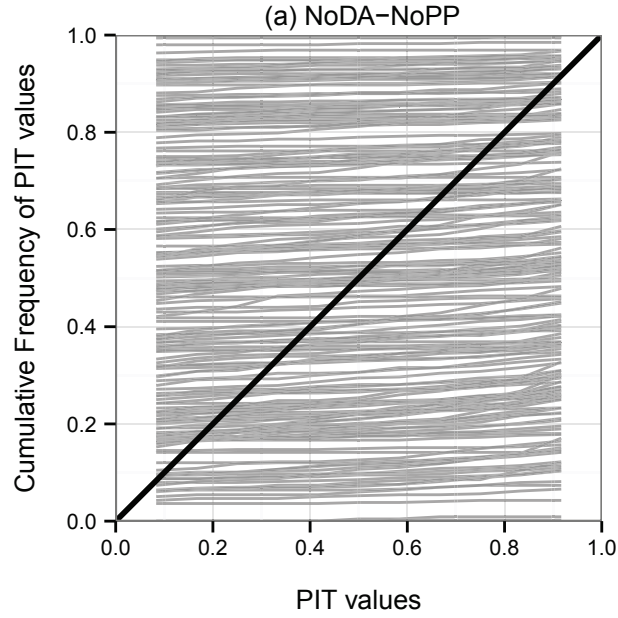

(c) NoDA-PP

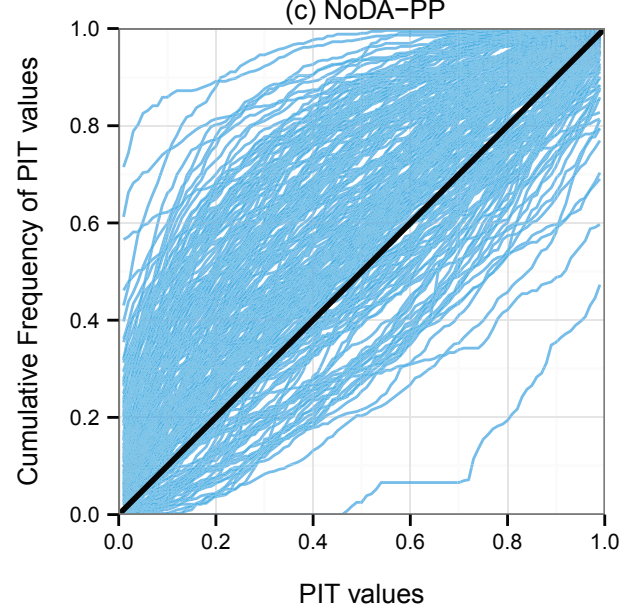

(b) DA-NoPP

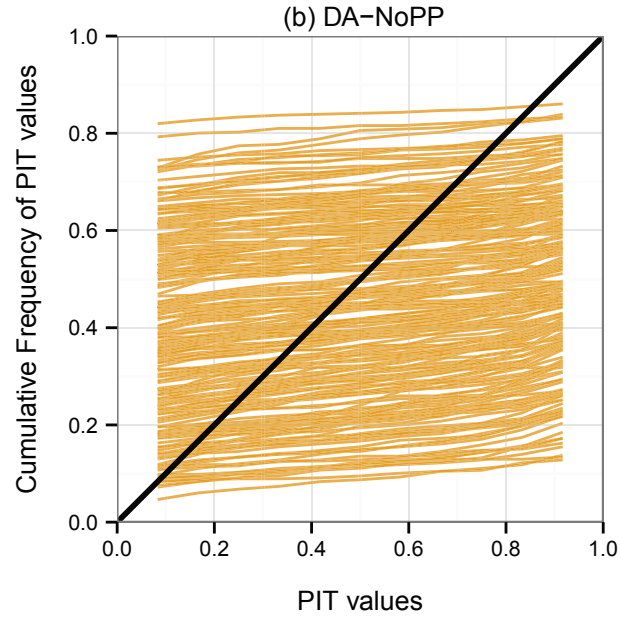

(d) DA-PP

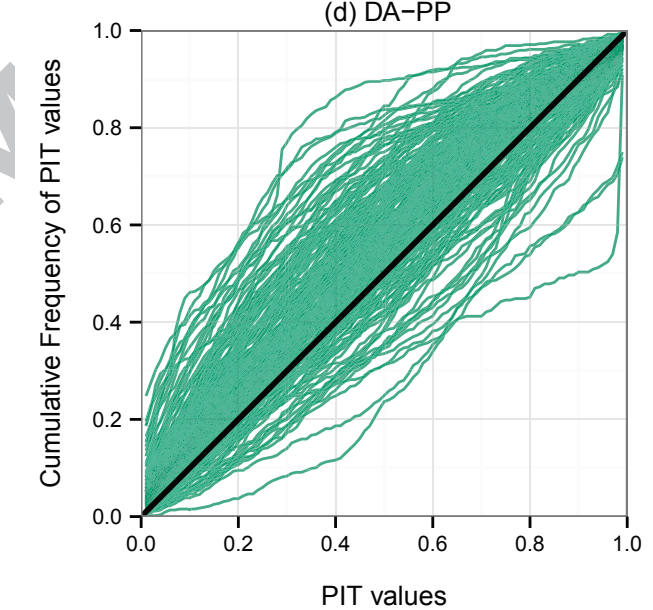

Figure 3: PIT diagrams of the $24 \mathrm{~h}$ ahead streamflow ensemble forecasts from the four experiments (see Table 2). Each line represents one of the 202 catchments of the data set. 
reliability. Their alpha values are almost always below 0.5 , while the alpha values obtained when hydrological uncertainty is taken into account (NoDA$\mathrm{PP}$ and DA-PP) are almost always higher than 0.5. The benefits of DA is also apparent when comparing, on one hand NoDA-NoPP and DA-NoPP, and on the other hand NoDA-PP and DA-PP, although it can be also seen that DA alone (comparing NoDA-NoPP to DA-NoPP) cannot correct under dispersion of the ensemble forecasts. Post-processing is then a necessary step to achieve reliable forecasts in the forecasting chain analysed.

These results suggest that for the 202 catchments studied the spread obtained by propagating solely the precipitation ensembles into the hydrological model is too small to properly reflect the range of forecast errors. The deterministic data assimilation strategy used here is effective in improving the reliability of the ensemble forecasts, but it is not self-sufficient to correct the under dispersion of the streamflow ensemble forecasts as revealed by the PIT diagrams in Figure 3 and the alpha scores in Figure 4. This is a strong indication that the hydrological uncertainty issue should be specifically addressed in order to improve the overall reliability of hydrological ensemble forecasts.

\subsection{Sharpness}

Sharpness is a desirable characteristic of any probabilistic forecast. The sharper the forecast, the less uncertain it is, and thus the more information is conveyed. The four experiments we used made it possible to investigate how meteorological and hydrological uncertainties interact and affect sharpness. Figure 5 shows the distributions of a sharpness index, the normalized mean interquartile range (NMIQR), over 202 catchments. 


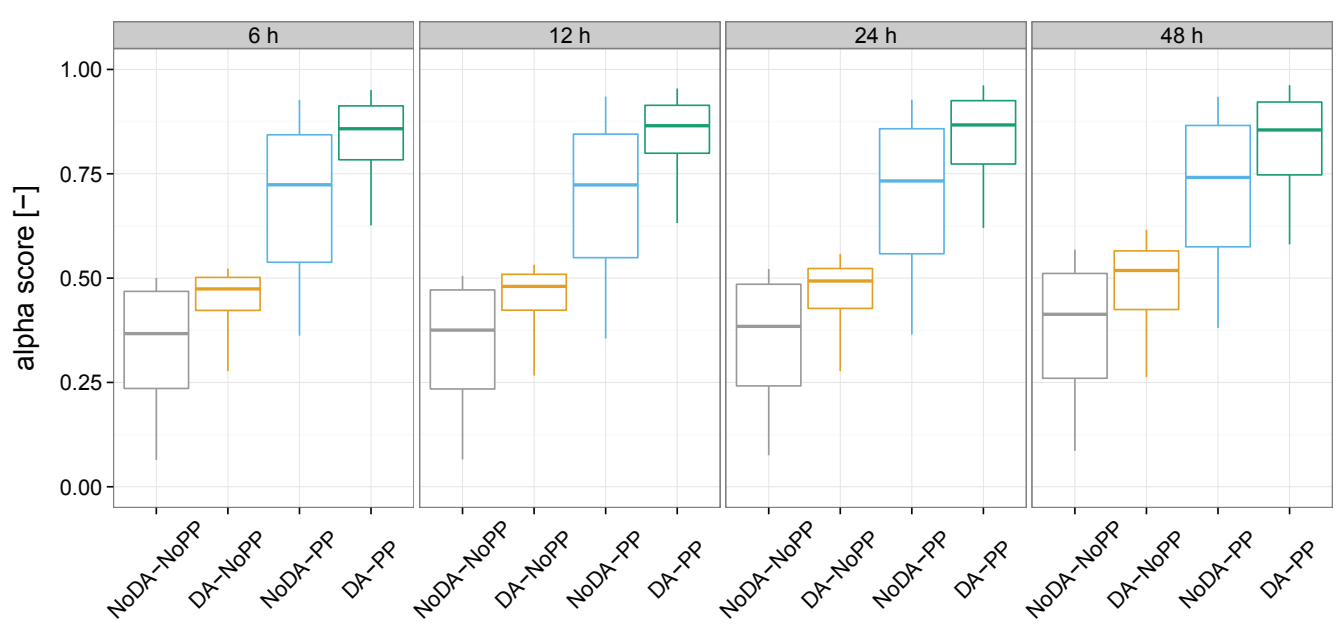

Figure 4: Distributions of the alpha score reliability index for streamflow ensemble forecasts from the four experiments (see Table 2) and for lead times $6 \mathrm{~h}, 12 \mathrm{~h}, 24 \mathrm{~h}$ and $48 \mathrm{~h}$. Boxplots (5th, 25th, 50th, 75th and 95th percentiles) synthesize the variety of scores over the 202 catchments of the data set. Perfect score is 1.0 . 
It can be seen that the ensemble spreads of three experiments, NoDANoPP, DA-NoPP and DA-PP, increase significantly with increasing lead time, while it is more stable over lead times for the experiment NoDA-PP. For NoDa-NoPP and DA-NoPP, the median value of NMIQR over the 202 catchments raises in a very close behaviour for both experiments, from around 0.05 for $6 \mathrm{~h}$ ahead forecasts to 0.13 for $48 \mathrm{~h}$ ahead forecasts. For the experiment $\mathrm{DA}-\mathrm{PP}$, the increase in the median values is much more important: from 0.07 at $6 \mathrm{~h}$ to 0.32 at $48 \mathrm{~h}$. These results indicate that forecast uncertainty increases with increasing lead time as the result of increasing meteorological uncertainty alone (NoDA-NoPP and DA-NoPP) or as the result of increasing meteorological and hydrological uncertainties considered together and with DA (DA-PP). Comparing DA-NoPP and DA-PP reveals the impact of post-processing: taking into account hydrological uncertainty leads to more spread and less sharpness in ensemble forecasts. Comparing NoDA-NoPP and DA-NoPP shows that the propagation of meteorological uncertainty has a rather similar impact on ensemble sharpness whether or not DA is used to update the states of the forecasting model. Remarkably, the ensemble spreads obtained without DA but with post-processing (NoDA-PP) is stable across the lead times with a median value over the 202 catchments around 0.52 . This is because statistical post-processing reflects the large errors obtained when the forecasting model does not use DA (see Figure 2). In this case, the spread obtained when taking hydrological uncertainty into account is so large that the increasing spread of the PEARP ensemble forecasts with increasing lead time has no visible impact on the spread of the post-processed ensemble: hydrological uncertainty dominates meteorological uncertainty. 
Not surprisingly, sharper forecasts are obtained when only meteorological uncertainty is taken into account (NoPP experiments). This is to the detriment of reliability: ensemble forecasts with only meteorological uncertainty are sharper but not reliable, reflecting the presence of under dispersion (as shown in Section 3.2). The use of post-processing (PP experiments) leads to ensembles that are more spread out because they attempt to handle hydrological uncertainty and reflect hydrological forecast errors. Ensembles are thus less sharp but, on the other hand, achieve reliability. At this point, it should be remembered that sharp but unreliable forecasts should be considered with caution. Unreliable forecasts can convey a wrong impression of certainty that results from having neglected one or several important sources of uncertainty.

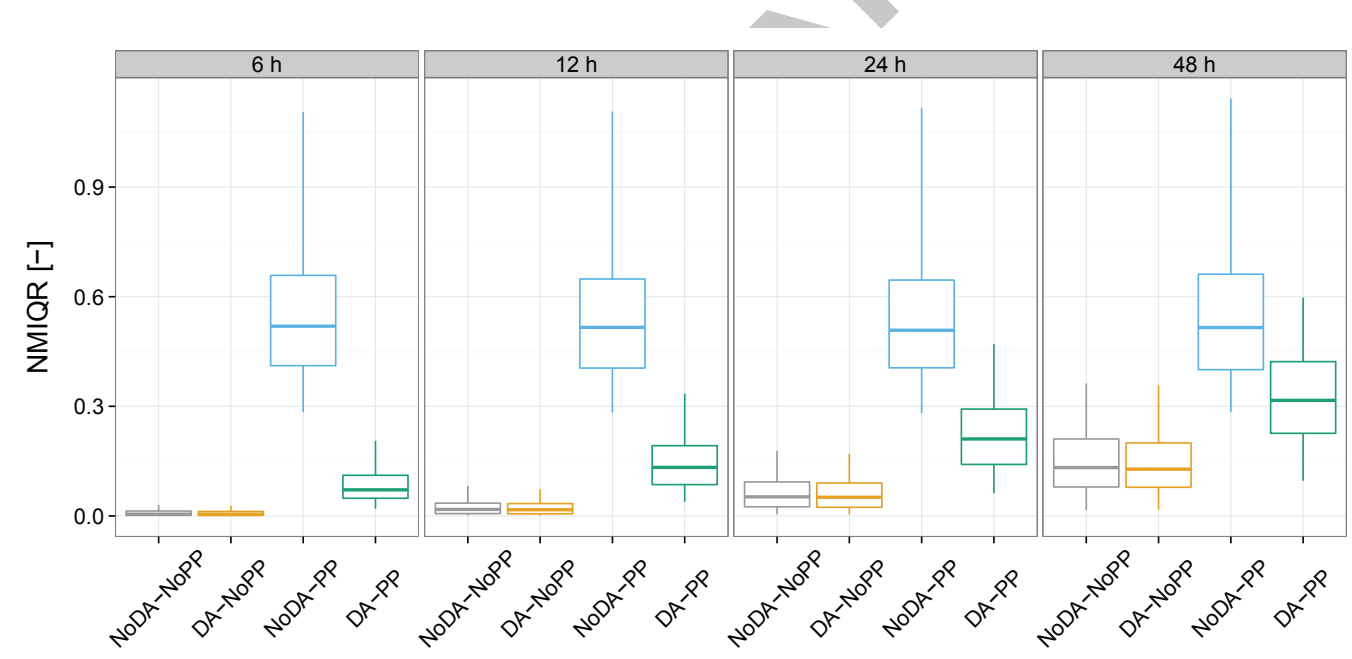

Figure 5: Distributions of the normalized mean interquartile range (NMIQR) for streamflow ensemble forecasts from the four experiments (see Table 2) and for lead times $6 \mathrm{~h}$, $12 \mathrm{~h}, 24 \mathrm{~h}$ and $48 \mathrm{~h}$. Boxplots (5th, 25th, 50th, 75th and 95th percentiles) synthesize the variety of scores over the 202 catchments of the data set. Perfect score is 0 . 


\subsection{Mean CRPSS}

The analysis of the impacts of data assimilation and post-processing on two important characteristics of probabilistic forecasts, reliability and sharpness, showed that post-processing was necessary to improve reliability, but at the cost of lower sharpness, i.e., greater ensemble spread and uncertainty, even if sharpness could be improved with the application of a data assimilation procedure. We now turn our attention to the mean CRPSS, a probabilistic score that provides an assessment of the overall quality of ensemble forecasts.

Figure 6 shows the distributions of the mean CRPSS over 202 catchments. We note that performance decreases with increasing lead time for the two experiments with data assimilation: median values of the CRPSS are equal to 0.84 (DA-NoPP) and 0.87 (DA-PP) for $6 \mathrm{~h}$ range forecasts, and equal to 0.45 (DA-NoPP) and 0.57 (DA-PP) for $48 \mathrm{~h}$ range forecasts. Mean CRPSS values of the two experiments without data assimilation decrease only slightly but are much lower than values obtained with data assimilation (median values around 0.10 for NoDA-NoPP and around 0.45 for NoDA-PP). This is especially true for shorter lead times and, to a lower extent, for larger lead times. Furthermore, the comparison with the reference climatology shows that data assimilation alone is sufficient to generate skillfull forecasts for more than $95 \%$ of the catchments for lead times up to $24 \mathrm{~h}$, but post-processing (DA$\mathrm{PP})$ is necessary to achieve forecasts that have better overall performance than climatology at $48 \mathrm{~h}$.

These results show the general added value of data assimilation and postprocessing to the overall quality of ensemble forecasts. When evaluating the 


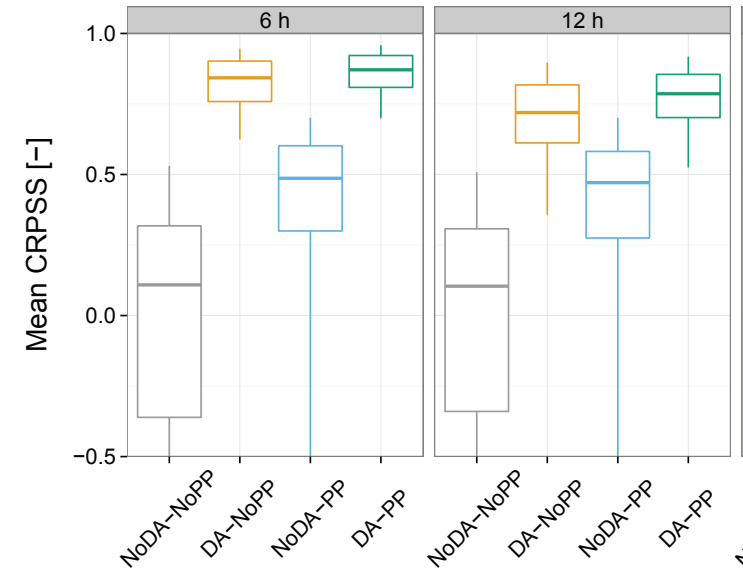
forecasts.

overall quality of ensemble forecasts with the CRPSS, the benefits in terms of reliability overcome the loss of sharpness that results from accounting for hydrological uncertainty. The streamflow ensemble forecasts that explicitly account for both sources of uncertainty, meteorological and hydrological uncertainties, through post-processing, while reducing as much as possible hydrological uncertainty, here through data assimilation, are the most skillfull

Figure 6: Distributions of the mean CRPSS for streamflow ensemble forecasts from the four experiments (see Table 2) and for lead times $6 \mathrm{~h}, 12 \mathrm{~h}, 24 \mathrm{~h}$ and $48 \mathrm{~h}$. Boxplots (5th, 25th, 50th, 75th and 95th percentiles) synthesize the variety of scores over the 202 catchments of the data set. Perfect score is 1.0.

\section{Summary and conclusions}

We investigated the relative contributions of data assimilation and post415 processing to the skill of hydrological ensemble forecasts. The study as416 sessed the benefits of data assimilation and post-processing with the help of 
four configurations of a short-range hydrological ensemble forecasting system: without data assimilation and post-processing (NoDA-NoPP), without data assimilation but with post-processing (NoDA-PP), with data assimilation but without post-processing (DA-NoPP), and with both data assimilation and post-processing (DA-PP).

We applied deterministic and probabilistic scores to streamflow forecasts of a large catchment set which brought into light the main general conclusions listed below:

- We verify the well-known fact that short-range hydrological forecasts benefit from data assimilation. Data assimilation has a strong impact on improving the quality of the ensemble mean, and a much lesser effect on the variability of the ensemble members (i.e., their spread).

- The benefits of a simple yet efficient hydrological uncertainty processor to improve the reliability and the overall quality of the short-range hydrological ensemble forecasts were demonstrated. Post-processing has a strong impact on forecast reliability.

- The benefits of the combined use of data assimilation and post-processing were demonstrated: both contribute to achieve reliable and sharp forecasts, with impacts acting differently according to the target lead time. The stronger impact on forecast reliability comes from the use of postprocessing. Adding data assimilation to the system helps in improving sharpness and reliability at all lead times, with higher gains in performance at shorter lead times.

We acknowledge some limitations. It was only possible to evaluate the 
forecasting chain over a 17-month period of ensemble forecasts, since this was the common period between observations and forecasts we had available. Furthermore, PEARP ensembles are ran only once a day, which limits the number of hourly evaluation pairs. For these reasons, it was not possible to evaluate flows over specific flooding thresholds . However, with increasing data archives, we expect that such an issue will be treated in future work.

Our study considered only one data assimilation technique (state updating with error output correction) and one post-processing method (ensemble dressing with hydrological errors) together with one rainfall-runoff model forecasting (GRP model). There are several other techniques and models in the literature that could also be tested using the methodology presented here. For instance, a comparison between different configurations of the method used, or different hydrological uncertainty processors, including methods that take into account the autocorrelation of errors (e.g., Schoups and Vrugt, 2010) could be investigated. Besides, while a bias correction was applied to the PEARP forecasts, a more sophisticated pre-processor (see e.g., Verkade et al., 2013) could be used to further investigate how meteorological and hydrological biases interact and contribute to the quality of the final hydrological ensemble.

Also, the effectiveness of a data assimilation technique or a post- processing method (and hence the choice of the procedures to operate in a forecasting system) is affected by different sources of uncertainties present in a flow forecasting system, including the forcing data, initial conditions, parameter uncertainty and model structural uncertainty. In our study, we followed the works of Krzysztofowicz (1999) and focused on a decomposition of the total 
uncertainty into meteorological and hydrological uncertainty. Observational or parameter uncertainties were thus not explicitly considered. Additional sources of uncertainty may however affect the performance of data assimilation techniques and post-processors, as well as the way they interact in the forecasting system. Further investigations would be necessary to better assess the extent to which this may affect forecast quality.

Although our findings may be related to the configuration used, they are based on common techniques and on the study of a large set of catchments, which helps in giving robustness and generality to the results obtained. The study also shows that, for a given system configuration, it is interesting to analyse how data assimilation and/or post-processing techniques set up to improve forecast quality affect the attributes of the forecasts and interact to provide overall good forecasts. The aim of a forecaster may then be to achieve a good combination of hydrological model, data assimilation and post-processing procedures that results in an overall good quality of his/her operational system (eventually over specific space and time scales of interest), rather than to search for the best data assimilation technique or post-processor available, without taking into account how they will interact between them and with the probabilistic forecasting system as a whole.

Despite those limitations, our results strongly suggest that data assimilation and post-processing techniques based on hydrological uncertainty processors should be more widely tested to foster their implementation in preoperational and operational hydrological ensemble forecasting systems and their use in real-time probabilistic forecasting. The use of both strategies is highly recommended since they have complementary effects: data assimila- 
491

tion has a very positive effect on forecast accuracy, and thus helps reduce

hydrological uncertainty, but its impact diminishes with lead time, while post-processing, by accounting for hydrological uncertainty, has a very positive and longer lasting effect on forecast reliability. 
495

496

\section{A. Evaluation scores}

The evaluation scores used in this article are defined and briefly described below. For more details, the reader may refer to Wilks (2011).

\section{A.1. Relative Bias}

The relative bias (BIAS) is defined as the ratio between the mean of deterministic forecasts and the mean of observations,

$$
\operatorname{BIAS}=\frac{\sum_{k=1}^{N} Q_{f c t}(k)}{\sum_{k=1}^{N} Q_{o b s}(k)}
$$

where $\left(Q_{f c t}(k), Q_{o b s}(k)\right)$ is the $k$ th of $N$ pairs of deterministic forecasts and observations.

Values higher (lower) than 1 indicate an overall overestimation (underestimation) of the observed values.

\section{A.2. Normalized root-mean-square error}

The root-mean-square error (RMSE) is a widely used measure of accuracy for point forecasts,

$$
\mathrm{RMSE}=\left[\frac{1}{N} \sum_{k=1}^{N}\left(Q_{f c t}(k)-Q_{o b s}(k)\right)^{2}\right]^{1 / 2}
$$

where $\left(Q_{f c t}(k), Q_{o b s}(k)\right)$ is the $k$ th of $N$ pairs of forecasts and observations. The lower the RMSE, the better. For a perfect deterministic forecast, $\mathrm{RMSE}=0$.

The normalized root-mean-square error (NRMSE) is obtained by dividing 512 the RMSE by the mean runoff. The use of a non-dimensional score facilitates the comparison of the results obtained over different catchments. 


\section{A.3. PIT diagram and alpha score}

The Probability Integral Transform (PIT) diagram is a graphical tool used to assess the reliability of probabilistic forecasts (Gneiting et al., 2007; Laio and Tamea, 2007). The PIT diagram corresponds to the empirical cumulative distribution of the PIT values, which are defined for each pair of forecasts and observations as the value that the cumulative predictive distribution $F$ reaches at the observation, $p^{o b s}=F\left(Q_{o b s}\right)$. It is analogous to a cumulated version of the rank histogram. If the forecasts are reliable, the PIT values follow a uniform distribution on the interval $[0,1]$ and the PIT curve is close to the 1:1 line. Reliability of the probabilistic forecasts implies that the observations should not be preferentially located in specific parts of the predictive distributions, but instead should uniformly span the whole predictive range.

The alpha score is an index proposed by Renard et al. (2010) to reflect the overall reliability of probabilistic forecasts. The alpha score is directly related to the PIT diagram. It is defined as $1-2 A$, where $A$ is the area between the bisector and the PIT curve,

$$
A=\frac{1}{N} \sum_{k=1}^{N}\left|p^{o b s}(k)-p^{t h}(k)\right|
$$

and where $\left(p^{o b s}(k), p^{t h}(k)\right)$ is the $k$ th of $N$ pairs of observed and theoretical PIT values.

The alpha score ranges from 0 to 1 . 0 indicates poor reliability while values close to 1 indicate perfect reliability. 

${ }_{552}$ pairs of evaluation data: MIQR is computed as

\section{A.4. Normalized mean interquartile range}

To assess the sharpness of probabilistic forecasts, we defined the mean interquartile range (MIQR) as the mean of the interquartile range of forecasts over the evaluation data. The interquartile range, defined as the range between the upper quartile (75th percentile) and the lower quartile (25th percentile) of a distribution, is a robust measure of the spread of a distribution.

$$
\operatorname{MIQR}=\frac{1}{N} \sum_{k=1}^{N}\left(Q_{f c t}^{75}(k)-Q_{f c t}^{25}(k)\right)
$$

where $\left(Q_{f c t}^{25}(k), Q_{f c t}^{75}(k)\right)$ is the $k$ th of $N$ pairs of quartiles of the forecasts.

Similarly to the NRMSE, we divided the MIQR by the mean runoff to obtain a non-dimensional score.

\section{A.5. Mean CRPS and mean CRPSS}

For a forecast-observation evaluation pair, the Continuous Rank Probability Score (CRPS) (e.g., Matheson and Winkler, 1976; Gneiting et al., 2007) measures the quadratic distance between two cumulative distribution functions, the cumulative predictive distribution $F(x)$ and a Heaviside function based on the observed value $\left.\mathbb{1}\left\{Q_{\text {obs }} \leqslant x\right\}\right)$ :

$$
\operatorname{CRPS}\left(F, Q_{o b s}\right)=\int_{-\infty}^{\infty}\left(F(x)-\mathbb{1}\left\{Q_{o b s} \leqslant x\right\}\right)^{2} d x
$$

The mean CRPS, $\overline{\mathrm{CRPS}}$, is the average value of the CRPS over the $N$

$$
\overline{\mathrm{CRPS}}=\frac{1}{N} \sum_{k=1}^{N} \operatorname{CRPS}(\mathrm{k})
$$


The mean Continuous Rank Probability Skill Score (CRPSS) is a skill score based on the CRPS. Skill scores (SS) are used to assess the relative quality of two forecasting systems. They are generally defined as:

$$
\mathrm{SS}=1-\frac{\text { Score }^{A}}{\text { Score }^{B}}
$$

where Score $^{A}$ and Score $^{B}$ are the scores of the forecasting system A and $\mathrm{B}$ respectively. The forecasting system B is usually termed the reference forecast.

Climatology is commonly used as a reference. To compute the mean CRPSS with the unconditional climatology as the reference, an unconditional streamflow ensemble forecast is first obtained from the empirical distribution of all observed discharges over the evaluation period, and then used for all forecast occasions.

\section{Acknowledgments}

The authors thank Météo-France for providing the meteorological data and Banque HYDRO for the hydrological data. The financial support of SCHAPI to the first author is also gratefully acknowledged.

The authors thank Dr. Thomas Pagano, two anonymous reviewers, and the Guest Editor Hamid Moradkhani for their critical and constructive evaluation of the manuscript, which helped improving its quality.

\section{References}

Andréassian, V., Lerat, J., Loumagne, C., Mathevet, T., Michel, C., Oudin, L., Perrin, C., 2007. What is really undermining hydrologic science today? Hydrological Processes 21, 2819-2822. doi:10.1002/hyp.6854. 
Berthet, L., Andreassian, V., Perrin, C., Javelle, P., 2009. How crucial is it to account for the antecedent moisture conditions in flood forecasting? Comparison of event-based and continuous approaches on 178 catchments. Hydrology and Earth System Sciences 13, 819-831.

Boucher, M.A., Tremblay, D., Delorme, L., Perreault, L., Anctil, F., 2012. Hydro-economic assessment of hydrological forecasting systems. Journal of Hydrology 416, 133-144. doi:10.1016/j.jhydrol.2011.11.042.

Brown, J.D., Seo, D.J., 2010. A Nonparametric Postprocessor for Bias Correction of Hydrometeorological and Hydrologic Ensemble Forecasts. Journal of Hydrometeorology 11, 642-665. doi:10.1175/2009JHM1188.1.

Brown, J.D., Seo, D.J., 2013. Evaluation of a nonparametric post-processor for bias correction and uncertainty estimation of hydrologic predictions. Hydrological Processes 27, 83-105. doi:10.1002/hyp.9263.

Cloke, H.L., Pappenberger, F., 2009. Ensemble flood forecasting: A review. Journal of Hydrology 375, 613-626. doi:10.1016/j.jhydrol.2009.06.005.

Coccia, G., Todini, E., 2011. Recent developments in predictive uncertainty assessment based on the model conditional processor approach. Hydrology and Earth System Sciences 15, 3253-3274. doi:10.5194/hess-15-3253-2011.

Ewen, J., O'Donnell, G., 2012. Prediction intervals for rainfall-runoff models: raw error method and split-sample validation. Hydrology Research 43, 637-648. doi:10.2166/nh.2012.038.

Fortin, V., Favre, A.C., Said, M., 2006. Probabilistic forecasting from ensemble prediction systems: Improving upon the best-member method by using 
a different weight and dressing kernel for each member. Quarterly Journal of the Royal Meteorological Society 132, 1349-1369. doi:10.1256/qj.05.167.

Gneiting, T., Balabdaoui, F., Raftery, A.E., 2007. Probabilistic forecasts, calibration and sharpness. Journal of the Royal Statistical Society Series B-Statistical Methodology 69, 243-268. doi:10.1111/j.14679868.2007.00587.x.

Hopson, T.M., Webster, P.J., 2010. A 1-10-Day Ensemble Forecasting Scheme for the Major River Basins of Bangladesh: Forecasting Severe Floods of 2003-07. Journal of Hydrometeorology 11, 618-641. doi:10.1175/2009jhm1006.1.

Krzysztofowicz, R., 1999. Bayesian theory of probabilistic forecasting via deterministic hydrologic model. Water Resources Research 35, 2739-2750.

Laio, F., Tamea, S., 2007. Verification tools for probabilistic forecasts of continuous hydrological variables. Hydrology and Earth System Sciences 11, 1267-1277.

Liu, Y., Weerts, A.H., Clark, M., Franssen, H.J.H., Kumar, S., Moradkhani, H., Seo, D.J., Schwanenberg, D., Smith, P., van Dijk, A., van Velzen, N., He, M., Lee, H., Noh, S.J., Rakovec, O., Restrepo, P., 2012. Advancing data assimilation in operational hydrologic forecasting: progresses, challenges, and emerging opportunities. Hydrology and Earth System Sciences 16, 3863-3887. doi:10.5194/hess-16-3863-2012.

${ }_{619}$ Matheson, J.E., Winkler, R.L., 1976. Scoring rules for continu- 
ous probability distributions. Management Science 22, 1087-1096. doi:10.1287/mnsc.22.10.1087.

Montanari, A., Brath, A., 2004. A stochastic approach for assessing the uncertainty of rainfall-runoff simulations. Water Resources Research 40, W01106. doi:10.1029/2003wr002540.

Montanari, A., Grossi, G., 2008. Estimating the uncertainty of hydrological forecasts: A statistical approach. Water Resources Research 44, W00B08. doi:10.1029/2008wr006897.

Moradkhani, H., DeChant, C.M., Sorooshian, S., 2012. Evolution of ensemble data assimilation for uncertainty quantification using the particle filter-Markov chain Monte Carlo method. Water Resources Research 48, W12520. doi:10.1029/2012wr012144.

Morawietz, M., Xu, C.Y., Gottschalk, L., Tallaksen, L.M., 2011. Systematic evaluation of autoregressive error models as post-processors for a probabilistic streamflow forecast system. Journal of Hydrology 407, 58-72. doi:10.1016/j.jhydrol.2011.07.007.

Nicolau, J., 2002. Short-range ensemble forecasting, in: Proceedings WMO/CBS Technical Conferences On Data Processing and Forecasting Systems, Cairns, Australia, pp. 2-3.

Oudin, L., Hervieu, F., Michel, C., Perrin, C., Andreassian, V., Anctil, F., Loumagne, C., 2005. Which potential evapotranspiration input for a lumped rainfall-runoff model? Part 2 - Towards a simple and efficient 
potential evapotranspiration model for rainfall-runoff modelling. Journal of Hydrology 303, 290-306. doi:10.1016/j.jhydrol.2004.08.026.

Pagano, T.C., Shrestha, D.L., Wang, Q.J., Robertson, D., Hapuarachchi, P., 2013. Ensemble dressing for hydrological applications. Hydrological Processes 27, 106-116. doi:10.1002/hyp.9313.

Perrin, C., Michel, C., Andreassian, V., 2003. Improvement of a parsimonious model for streamflow simulation. Journal of Hydrology 279, 275-289. doi:10.1016/s0022-1694(03)00225-7.

Pianosi, F., Raso, L., 2012. Dynamic modeling of predictive uncertainty by regression on absolute errors. Water Resources Research 48, W03516. doi:10.1029/2011wr010603.

Randrianasolo, A., Ramos, M.H., Thirel, G., Andreassian, V., Martin, E., 2010. Comparing the scores of hydrological ensemble forecasts issued by two different hydrological models. Atmospheric Science Letters 11, 100107. doi:10.1002/asl.259.

Reggiani, P., Renner, M., Weerts, A.H., van Gelder, P., 2009. Uncertainty assessment via Bayesian revision of ensemble streamflow predictions in the operational river Rhine forecasting system. Water Resources Research 45, W02428. doi:10.1029/2007wr006758.

Renard, B., Kavetski, D., Kuczera, G., Thyer, M., Franks, S.W., 2010. Understanding predictive uncertainty in hydrologic modeling: The challenge of identifying input and structural errors. Water Resources Research 46, W05521. doi:10.1029/2009wr008328. 
Salamon, P., Feyen, L., 2010. Disentangling uncertainties in distributed hydrological modeling using multiplicative error models and sequential data assimilation. Water Resources Research 46, W12501. doi:10.1029/2009wr009022.

Schoups, G., Vrugt, J.A., 2010. A formal likelihood function for parameter and predictive inference of hydrologic models with correlated, heteroscedastic, and non-Gaussian errors. Water Resources Research 46, W10531. doi:10.1029/2009wr008933.

Smith, P.J., Beven, K.J., Weerts, A.H., Leedal, D., 2012. Adaptive correction of deterministic models to produce probabilistic forecasts. Hydrology and Earth System Sciences 16, 2783-2799. doi:10.5194/hess-16-2783-2012.

Solomatine, D.P., Shrestha, D.L., 2009. A novel method to estimate model uncertainty using machine learning techniques. Water Resources Research 45, W00B11. doi:10.1029/2008wr006839.

Tabary, P., Dupuy, P., L’Henaff, G., Gueguen, C., Moulin, L., Laurantin, O., Merlier, C., Soubeyroux, J.M., 2012. A 10-year (1997-2006) reanalysis of Quantitative Precipitation Estimation over France: methodology and first results, in: Weather Radar and Hydrology, IAHS. pp. 255-260.

Thirel, G., Rousset-Regimbeau, F., Martin, E., Habets, F., 2008. On the Impact of Short-Range Meteorological Forecasts for Ensemble Streamflow Predictions. Journal of Hydrometeorology 9, 1301-1317. doi:10.1175/2008jhm959.1. 
Thyer, M., Renard, B., Kavetski, D., Kuczera, G., Franks, S.W., Srikanthan, S., 2009. Critical evaluation of parameter consistency and predictive uncertainty in hydrological modeling: A case study using Bayesian total error analysis. Water Resources Research 45, W00B14. doi:10.1029/2008wr006825.

Van Steenbergen, N., Ronsyn, J., Willems, P., 2012. A non-parametric data-based approach for probabilistic flood forecasting in support of uncertainty communication. Environmental Modelling \& Software 33. doi:10.1016/j.envsoft.2012.01.013.

Verkade, J.S., Brown, J.D., Reggiani, P., Weerts, A.H., 2013. Post-processing ecmwf precipitation and temperature ensemble reforecasts for operational hydrologic forecasting at various spatial scales. Journal of Hydrology 501, 73-91. Times Cited: 00.

Vidal, J.P., Martin, E., Franchisteguy, L., Baillon, M., Soubeyroux, J.M., 2010. A 50-year high-resolution atmospheric reanalysis over France with the Safran system. International Journal of Climatology 30, 1627-1644. doi:10.1002/joc.2003.

Vrugt, J.A., ter Braak, C.J.F., Diks, C.G.H., Schoups, G., 2013. Hydrologic data assimilation using particle Markov chain Monte Carlo simulation: Theory, concepts and applications. Advances in Water Resources 51, $457-$ 478. doi:10.1016/j.advwatres.2012.04.002.

Wang, X., Bishop, C., 2005. Improvement of ensemble reliability with a new 
dressing kernel. Quarterly Journal of the Royal Meteorological Society 131, 965-986. doi:10.1256/qj.04.120.

Weerts, A.H., El Serafy, G.Y.H., 2006. Particle filtering and ensemble Kalman filtering for state updating with hydrological conceptual rainfall-runoff models. Water Resources Research 42, W09403. doi:10.1029/2005wr004093.

Weerts, A.H., Winsemius, H.C., Verkade, J.S., 2011. Estimation of predictive hydrological uncertainty using quantile regression: examples from the National Flood Forecasting System (England and Wales). Hydrology and Earth System Sciences 15, 255-265. doi:10.5194/hess-15-255-2011.

Wilks, D.S., 2011. Statistical methods in the atmospheric sciences. 3rd ed., Academic, Oxford.

Yan, J., Liao, G.Y., Gebremichael, M., Shedd, R., Vallee, D.R., 2012. Characterizing the uncertainty in river stage forecasts conditional on point forecast values. Water Resources Research 48, W12509. doi:10.1029/2012wr011818.

Zalachori, I., Ramos, M.H., Garçon, R., Mathevet, T., Gailhard, J., 2012. Statistical processing of forecasts for hydrological ensemble prediction: a comparative study of different bias correction strategies. Advances in Science and Research 8, 135-141. doi:10.5194/asr-8-135-2012. 
Figure 3. PIT diagrams of the $24 \mathrm{~h}$ ahead streamflow ensemble forecasts from the four a-d) experiments (see Table 2). Each line represents one of the 202 catchments of the data set. 


\section{Highlights}

- Data assimilation and post-processing impact hydrologic ensemble forecasts' skill.

- Data assimilation has a strong impact on forecast accuracy.

- Post-processing has a strong impact on forecast reliability.

- The combined benefits of data assimilation and post-processing were demonstrated.

- We recommend the use of both data assimilation and post-processing in forecasting. 